\title{
PEMBELAJARAN RAMPAK KENDANG DENGAN BAHASA ISYARAT PADA SISWA TUNARUNGU DI SLB AISIYAH SINGAPARNA
}

\author{
Asti Tri Lestari \\ Universitas Muhammadiyah Tasikmalaya \\ Jl. Tamansari Km.1,5 Tamansari Kota Tasikmalaya \\ Email: trilestariasti@yahoo.com \\ Anggia Suci Pratiwi \\ Universitas Muhammadiyah Tasikmalaya \\ Jl. Tamansari Km.1,5 Tamansari Kota Tasikmalaya \\ Email: anggia@umtas.ac.id \\ Rikha Surtika Dewi \\ Universitas Muhammadiyah Tasikmalaya \\ Jl. Tamansari Km.1,5 Tamansari Kota Tasikmalaya \\ Email: rikha_sd@yahoo.com
}

\begin{abstract}
The research entitled "Learning Rampak Kendang with Sign Language to Deaf Students in SLB Aisiyah Singaparna" is aimed to know: (1) learning process of Rampak kendang with sign language on deaf students at SLB Aisiyah Singaparna, (2) obstacles faced by students hearing impaired in learning Rampak kendang at Aisiyah Singaparna SLB, and (3) learning result of Rampak kendang with sign language in SLB Aisiyah Singaparna. The method used is descriptive method. This method is used to provide an overview of the learning process Rampak kendang with sign language, the constraints faced by deaf students in learning Rampak kendang, and the picture of learning outcomes Rampak drums. After this research is expected to do further research with experimental method or method of Research and Development (R \& D), that is development of a media of learning in the form of digital media to help deaf student in learning rampak kendang or other learning. The result of this research showed that deaf students of SLB Aisyiyah were able to follow the learning of Rampak kendang through sign language instruction. The learning process of Rampak kendang was conducted as many as ten meetings in the Teaching and Learning Activities (KBM) and five meetings outside KBM. At the end of the lesson, the students perform the public drums. This is done to instill self-confidence of deaf students. Based on interviews with school principals and teachers, the constraints often faced by deaf students in learning, namely communication problems. Learning dance is not too experiencing constraints because it is visual, but the obstacles encountered when having to use music and change of movement. For music and movement harmony with disiasati coding, count, and tap. Students will have difficulty following learning if vision is detached from the teacher, so students' views are always focused.
\end{abstract}

Keywords:

Rampak Kendang; Sign language; Deaf; SLB

\begin{abstract}
ABSTRAK
Penelitian yang berjudul "Pembelajaran Rampak Kendang dengan Bahasa Isyarat pada Siswa Tunarungu di SLB Aisiyah Singaparna" ini bertujuan untuk mengetahui: (1) proses pembelajaran rampak kendang dengan bahasa isyarat pada siswa tunarungu di SLB Aisiyah Singaparna, (2) kendala-kendala yang dihadapi siswa tunarungu dalam pembelajaran rampak kendang di SLB Aisiyah Singaparna, dan (3) hasil pembelajaran rampak kendang dengan bahasa isyarat di SLB Aisiyah Singaparna. Metode yang digunakan adalah metode deskriptif. Metode ini digunakan untuk memberikan gambaran tentang proses pembelajaran rampak kendang dengan bahasa isyarat, kendala yang dihadapi siswa tunarungu dalam pembelajaran rampak kendang, serta gambaran hasil pembelajaran rampak kendang tersebut. Setelah penelitian ini diharapkan dapat dilakukan penelitian lanjutan dengan metode eksperimen ataupun metode Research and Development (R\&D), yaitu pengembangan sebuah media pembelajaran berupa media digital
\end{abstract}


untuk membantu siswa tunarungu dalam pembelajaran rampak kendang atau pembelajaran lainnya. Hasil penelitian menunjukkan bahwa siswa tunarungu SLB Aisyiyah mampu mengikuti pembelajaran rampak kendang melalui instruksi bahasa isyarat. Proses pembelajaran rampak kendang dilakukan sebanyak sepuluh kali pertemuan di dalam Kegiatan Belajar Mengajar (KBM) dan lima pertemuan di luar KBM. Di akhir pembelajaran, siswa menampilkan rampak kendang di depan umum. Hal ini dilakukan untuk menanamkan rasa percaya diri siswa tunarungu. Berdasarkan hasil wawancara dengan kepala sekolah dan guru, kendala yang sering dihadapi oleh siswa tunarungu dalam pembelajaran, yaitu masalah komunikasi. Pembelajaran tari tidak terlalu mengalamai kendala karena bersifat visual, namun kendala dihadapi saat harus menggunakan musik dan pergantian gerakan. Untuk keharmonisan musik dan gerak disiasati dengan pengkodean, hitungan, dan ketukan. Siswa akan mengalami kesulitan mengikuti pembelajaran jika penglihatan terlepas dari guru, maka pandangan siswa diusahakan selalu fokus.

Kata Kunci:

Rampak Kendang; Bahasa Isyarat; Tunarungu; SLB

\section{A. PENDAHULUAN}

Seni budaya khususnya seni tari adalah salah satu mata pelajaran yang harus disampaikan pada siswa, tidak terkecuali siswa di sekolah luar biasa (SLB). Kedudukan mata pelajaran Seni Budaya memiliki kedudukan yang sama penting dengan mata pelajaran lain, meskipun mata pelajaran Seni Budaya tidak termasuk mata pelajaran yang diujikan pada ujian nasional. Salah satu materi dalam mata pelajaran Seni Budaya yaitu rampak kendang. Pembelajaran rampak kendang tentunya akan sangat mudah diajarkan pada siswa sekolah umum, namun berbeda halnya jika disampaikan pada siswa di SLB. Pembelajaran rampak kendang di SLB disampaikan melalui bahasa isyarat.

Pemilihan materi rampak kendang didasarkan pada alasan bahwa para siswa berkebutuhan khusus, khususnya siswa tunarungu, disinyalir dapat mengikuti pembelajaran dengan bantuan bahasa isyarat. Selain itu, pembelajaran rampak kendang dapat dijadikan tempat penyaluran ekspresi siswa, wawasan, dan keterampilan seni.

Pembelajaran rampak kendang di SLB Aisiyah Singaparna menunjukan hasil yang kurang memuaskan. Banyak kendala yang dihadapi oleh pengajar, salah satunya siswa kesulitan mengikuti ritme musik dikarenakan terbentur keterbatasan fisik. Laporan tersebut didapat dari hasil pengamatan dan wawancara dengan beberapa orang siswa tunarungu yang mengikuti pelajaran seni. Oleh karena itu, dibutuhkan sarana komunikasi yang maksimal dalam penyampaian materi rampak kendang. Sarana yang dapat mempermudah komunikasi dengan siswa tunarungu adalah bahasa isyarat. Hal ini dikarenakan bahasa isyarat diproses melalui modalitas visual/ gestural (lawan dari vokal/oral untuk bahasa yang diucapkan).

Bahasa isyarat merupakan media yang dapat mempermudah komunikasi dengan siswa tunarungu (Cripps, J. H. \& Supalla, S. J, 2012). Hal ini karena bahasa diproses melalui modalitas visual/ gestural (lawan dari vokal/ oral untuk bahasa yang diucapkan). Literasi bahasa sulit dipahami oleh siswa tunarungu, terutama ketika siswa tunarungu tersebut sama sekali tidak menikmati akses pendengaran dengan bahasa yang terlibat. Namun, diharapkan siswa telah memiliki pengetahuan bahasa lisan dan keterampilan fonetik dalam membaca.

Sebuah batu sandungan dalam pemahaman instruksi bahasa isyarat terletak pada pengetahuan siswa tunarungu belum terhubung dengan pengembangan membaca dalam bahasa Indonesia. Kurangnya pemahaman guru, tentang bahasa isyarat tersebut berhubungan dengan bahasa lisan, dalam pengoptimalan bahasa isyarat merupakan salah satu 
kendala. Pertimbangan tipologis yang diusulkan merupakan kunci untuk memahami bahasa isyarat dan akan membantu menentukan bahwa bahasa Indonesia juga harus diperkenalkan di kelas tunarungu.

Pemahaman bahasa dan huruf adalah dua atribut penting untuk pendidikan siswa biasa, begitu juga bagi siswa tunarungu karena semua siswa layak mendapatkan pembelajaran yang sama. Oleh karena itu, perlu dilakukan penelitian agar pembelajaran untuk siswa tunarungu mulai terlepas dari kelemahan dalam teori dan praktik. Wawasan mengenai penguasaan bahasa isyarat oleh guru sangat penting dioptimalkan. Sebagai bagian dari pemahaman linguistik aksesibilitas bagi siswa tunarungu, struktur dari bahasa isyarat harus memenuhi prasyarat kognitif untuk persepsi dan pengolahan dalam modalitas visual/gestural.

Siswa dengan gangguan pendengaran atau yang sering disebut tunarungu seringkali menimbulkan masalah tersendiri. Masalah utama pada siswa tunarungu adalah masalah komunikasi. Ketidakmampuan siswa tunarungu berkomunikasi akan berdampak sangat luas, seperti pada keterampilan berbahasa maupun penyesuaian sosial serta prestasi di sekolah. Agar seorang siswa tunarungu dapat berkembang secara maksimal, maka perlu dipahami berbagai kebutuhannya. Jalur pendidikan formal merupakan salah satu upaya yang banyak dilakukan untuk membantu siswa tunarungu. Namun, agar pendidikan ini berhasil, perlu kerjasama antara orangtua, penanganan yang terintergrasi, dan pelayanan yang profesional.

Menurut Moores dalam Mangunsong (2009) definisi dari ketunarunguan adalah kondisi individu tidak mampu mendengar dan hal ini tampak dalam wicara atau bunyi-bunyian lain, baik dalam derajat frekuensi dan intensitas. Dampak ketunaan terhadap pendidikan sangat dipengaruhi oleh hakikat kerusakan secara kualitatif, derajat ketunaan, dan saat terjadinya.
Damak yang parah adalah apabila kerusakan pendengaran terjadi pada rentang frekuensi suara manusia. Ketunarunguan memiliki dampak yang sangat besar pada siswa terutama terhadap perkembangan bahasa, intelektual, kepribadian dan sosial. Interdependensi antara pendengaran dengan perkembangan bahasa sangat besar dan merupakan masalah yang besar bagi siswa tunarungu. Kepandaian berbicara berhubungan dengan tingkat kerusakan pendengaran dan usia awal munculnya kerusakan tersebut (Hallahan dalam Mangunsong, 2009).

Kesulitan pemahaman wicara pada siswa tunarungu yang berat atau parah merupakan hasil dari berbagai faktor, yaitu masalah dalam menghasilkan suara, kualitas suara yang buruk, ketidakmampuan membedakan nada, dan masalah yang berkaitan dengan konten dan struktur bahasa (Suran dan Rizzo dalam Mangunsong, 2009). Struktur yang dipergunakan siswa tunarungu berbeda apabila dibandingkan dengan siswa normal. Struktur kalimat yang digunakan siswa tunarungu lebih sederhana. Hal ini nampak pada bahasa tulis maupun lisan.

Sebagian besar siswa tunarungu sebenarnya memiliki minat yang tinggi dalam mempelajari rampak kendang. Hal tersebut dikarenakan terdapat korelasi antara rampak kendang, yang identik dengan permainan ritmik yang dinamis, dengan kultur masyarakat tempat tinggal. Siswa tidak saja mau bergerak meniru gerak yang terdapat dalam rampak kendang, tetapi juga berusaha menjiwai ritmik dan gerak-gerak dalam rampak kendang. Karena didasari oleh rasa senang terhadap rampak kendang tersebut, pembelajaran rampak kendang pun dapat disampaikan pada siswa tunarungu. Fenomena tingginya minat siswa tunarungu dalam mempelajari rampak kendang dapat dijadikan sebagai sebuah jalan dalam peningkatan kemampuan siswa terhadap gerak yang banyak digunakan di dalam pembelajaran Tari di 
Asti Tri Lestari, Anggia Suci Pratiwi

Rikha Surtika Dewi

sekolah dan kualitas pembelajaran seni di SLB Aisiyah Singaparna.

Rampak kendang merupakan salah satu kesenian tradisional yang berasal dari Jawa Barat. "Rampak" berasal dari bahasa sunda yang bermakna serempak atau secara bersama-sama, jadi rampak kendang bisa diartikan sebagai suatu pertunjukkan gendang yang dimainkan secara bersama-sama. Oleh karena itu, pertunjukkan kampak kendang selalu dimainkan oleh dua orang atau lebih. Gendang atau kendang merupakan alat musik utama dari pertunjukkan rampak kendang. Alat musik ini juga merupakan instrumen dalam gamelan jawa, yang berfungsi sebagai pengatur irama. Alat musik lainnya dalam pertunjukkan rampak kendang adalah rebab, terompet, dan gamelan. Semua alat musik itu dipadukan membentuk suatu irama yang energik dan bersemangat.

Kesenian rampak kendang merupakan representasi dari kebersahajaan masyarakat Sunda. Kesenian tersebut kaya akan nilai-nilai filosofis yang mencerminkan masyarakat Sunda yang guyub dan harmonis berlandaskan sifatsifat kegotong-royongan dan keceriaan. Satu lagi kekayaan nusantara bernilai dunia yang harus dijaga dan dilestarikan. Rampak kendang dari Indonesia untuk dunia. Kesenian ini berkembang pesat di berbagai daerah hampir di seluruh wilayah Jawa Barat termasuk Kabupaten Tasikmalaya. Perkembangan selanjutnya rampak kendang menggunakan beberapa orang wanita sebagai penari dengan koreografi yang menonjolkan gerakangerakan yang dinamis.

Berdasarkan uraian di atas, perlu dilakukan sebuah penelitian dalam peningkatan minat dan keterampilan siswa tunarungu terhadap pembelajaran seni tari melalui model pembelajaran rampak kendang. Adapun tujuan dari penelitian yang berjudul "Pembelajaran Rampak Kendang dengan Bahasa Isyarat pada Siswa Tunarungu di SLB Aisiyah Singaparna" untuk mengetahui :
Pembelajaran Rampak Kendang dengan Bahasa Isyarat pada Siswa

Tunarungu Di SLB Aisiyah Singaparna

1. Proses pembelajaran rampak kendang dengan bahasa isyarat pada siswa tunarungu di SLB Aisiyah Singaparna.

2. Kendala-kendala yang dihadapi siswa tunarungu dalam pembelajaran rampak kendang di SLB Aisiyah Singaparna.

3. Hasil pembelajaran rampak kendang dengan bahasa isyarat di SLB Aisiyah Singaparna.

Metode penelitian yang paling tepat digunakan adalah metode deskriptif. Metode deskriptif digunakan untuk memberikan gambaran tentang proses pembelajaran rampak kendang dengan bahasa isyarat pada siswa tunarungu di SLB Aisiyah Singaparna, kendala-kendala yang dihadapi siswa tunarungu dalam pembelajaran rampak kendang di SLB Aisiyah Singaparna, serta hasil pembelajaran rampak kendang dengan bahasa isyarat di SLB Aisiyah Singaparna.

\section{B. HASIL DAN PEMBAHASAN}

Hasil penelitian yang didapat dari penelitian pembelajaran rampak kendang melalui bahasa isyarat bagi siswa tunarungu di SLB Aisyiyah Singaparna. Hasil penelitian menyajikan data-data yang diperoleh dari hasil observasi, wawancara dengan kepala sekolah, guru, siswa, dan orangtua siswa. Selain itu, deskripsi proses pembelajaran rampak kendang selama sepuluh pertemuan akan disajikan dalam bentuk rekaman dan gambar. Data hasil penelitian ini dianalisis sesuai dengan teori yang dipakai, kemudian hasil analisis tersebut disajikan dalam bentuk tabel dan deskripsi verbal.

\section{Deskripsi Hasil Observasi}

Siswa tunarungu yang menjadi subjek penelitian ini terdiri dari lima orang siswa kelas 5 di SLB Aisyiyah Singaparna. Kelima siswa ini belum pernah mendapatkan pembelajaran rampak kendang sebelumnya. Siswa yang menjadi subjek penelitian ini, yaitu : 
Asti Tri Lestari, Anggia Suci Pratiwi Rikha Surtika Dewi

Tabel 1. Daftar Subjek Penelitian

\begin{tabular}{|c|l|c|}
\hline No. & Nama Siswa & Kelas \\
\hline 1. & Lia Hermawati & 5 \\
\hline 2. & $\begin{array}{l}\text { Ikhsan } \\
\text { Fardilah }\end{array}$ & 5 \\
\hline 3. & Deden Rifaidl & 5 \\
\hline 4. & Rayka Raika & 5 \\
\hline 5. & $\begin{array}{l}\text { Rahmat } \\
\text { Nursamsi }\end{array}$ & 5 \\
\hline
\end{tabular}

Guru yang terlibat dalam penelitian sebanyak tiga (3) orang guru, yaitu $\mathrm{Bu}$ Yani, Pak Agus, dan Bu Hani (guru honorer). Berdasarkan hasil observasi, pembelajaran rampak kendang di SLB Aisyiyah Singaparna ini belum menjadi pembelajaran inti dalam mata pelajaran Seni Budaya karena tidak ada guru pengampu. Oleh karena itu, guru biasanya didatangkan dari luar sekolah. Siswa tunarungu, guru, dan kepala sekolah antusias untuk terlibat dalam penelitian. Alat penelitian yang digunakan berupa lima set kendang dan ancak kendang. Keadaan kendang dan ancak kendang bagus dan laik pakai, namun ada satu kendang yang rusak di tengah penelitian, namun tidak menjadi kendala yang berarti. Kendang yang rusak tersebut bisa diperbaiki. Ruangan yang digunakan yaitu aula/ ruang pertemuan SLB Aisyiyah Singaparna.

\section{Deskripsi Hasil Wawancara}

Wawancara dilakukan dengan Kepala Sekolah SLB Aisyiyah dan dua orang guru kelas lima (5) SLB Aisyiyah.

\section{a. Wawancara dengan Kepala Sekolah}

Wawancara dengan Kepala Sekolah dilakukan untuk memperoleh data tentang pembelajaran Seni Budaya di SLB Aisyiyah, tanggapan tentang penelitian rampak kendang, dan kendala yang dihadapi dalam pembelajaran Seni Budaya, khususnya rampak kendang.

Berdasarkan hasil wawancara dengan kepala sekolah, kendala yang sering dihadapi oleh siswa tunarungu dalam pembelajaran, yaitu masalah
Pembelajaran Rampak Kendang dengan Bahasa Isyarat pada Siswa

Tunarungu Di SLB Aisiyah Singaparna

komunikasi. Pembelajaran tari tidak terlalu mengalamai kendala karena bersifat visual, namun kendala dihadapi saat harus menggunakan musik dan pergantian gerakan. Untuk keharmonisan musik dan gerak disiasati dengan pengkodean, hitungan, dan ketukan. Siswa akan mengalami kesulitan mengikuti pembelajaran jika penglihatan terlepas dari guru. Oleh karena itu, pandangan siswa diusahakan selalu fokus.

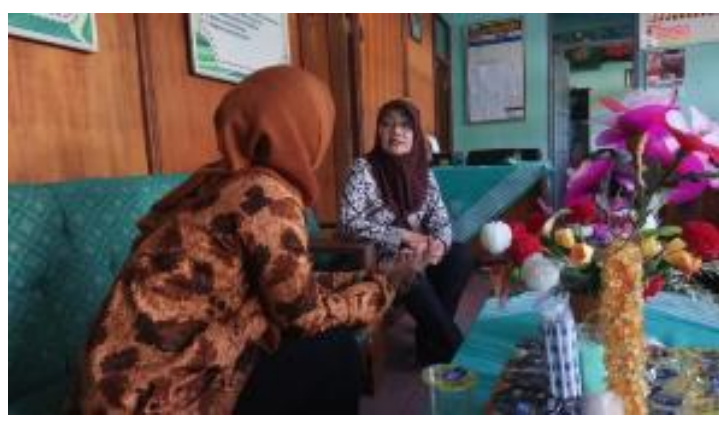

Gambar 1.

\section{Wawancara Kepala Sekolah SLB} Aisyiyah

b. Wawancara dengan Guru

Berdasarkan hasil wawancara dengan guru SLB Aisyiyah, pembelajaran rampak kendang pernah diberikan pada siswa tunarungu. Namun karena kendala guru yang mengajar Seni Budaya mengundurkan diri, pembelajaran rampak kendang dihentikan. Siswa yang dulu mendapatkan pembelajaran rampak kendang, saat ini kelas X SMA, masih di SLB Aisyiyah. Pihak sekolah sudah berusaha untuk mencari guru pengganti, namun belum mendapat. Hal ini diperkuat dengan hasil observasi bahwa ada seperangkat alat rampak kendang di aula SLB Aisyiyah. Guru menyambut dengan tangan terbuka adanya penelitian ini karena guru yakin bahwa Seni khususnya rampak kendang membawa dampak yang positif untuk siswa tunarungu, melatih rasa disiplin, fokus terhadap pembelajaran, percaya diri, dan yang penting mampu menerima informasi atau pembelajaran dengan cepat. 
Asti Tri Lestari, Anggia Suci Pratiwi

Rikha Surtika Dewi
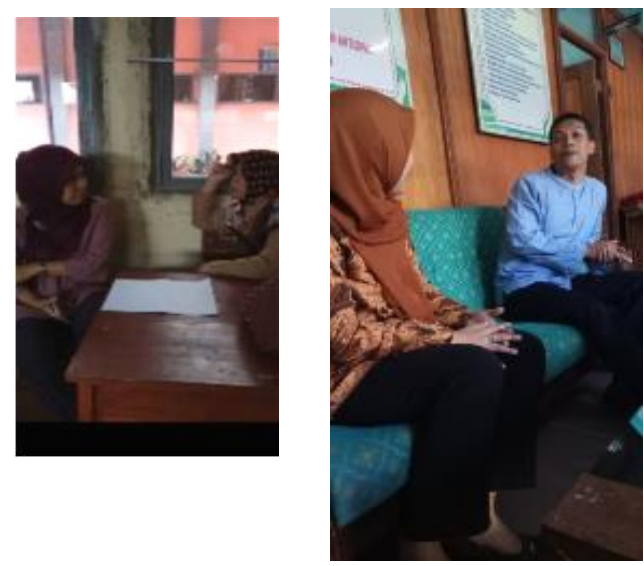

Gambar 2.

Wawancara dengan Guru SLB Aisyiyah

\section{Proses Pembelajaran Rampak \\ Kendang}

Pembelajaran rampak kendang melalui bahasa isyarat bagi siswa tunarungu di SLB Aisyiyah Singaparna dalam rangka Penelitian Dosen Pemula ini dilakukan sebanyak sepuluh kali pertemuan di dalam Kegiatan Belajar Mengajar (KBM) dan lima kali pertemuan di luar KBM. Di awal pertemuan siswa diperkenalkan dengan teori rampak kendang. Teori disampaikan dengan menggunakan bahasa isyarat sampai siswa paham tentang teori rampak kendang. Motif/ pola tabuh mulai diajarkan di pertemuan kedua. Satu pola tabuh diberikan di tiap satu pertemuan karena siswa tunarungu masih terlihat belum terbiasa untuk menabuh kendang. Pola yang diberikan terdiri dari 4 pola tabuh dan diiringi dengan musik tokecang. Adapun pola tabuh kendang dapat dilihat pada gambar berikut ini:
Pembelajaran Rampak Kendang dengan Bahasa Isyarat pada Siswa Tunarungu Di SLB Aisiyah Singaparna

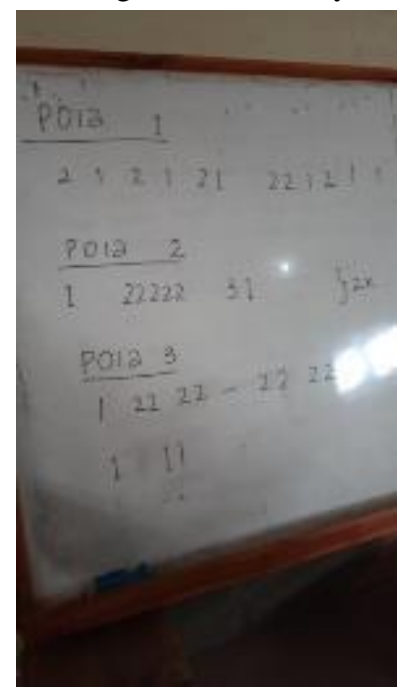

Gambar 3.

\section{Pola Tabuh Rampak Kendang}

Proses pembelajaran rampak kendang bagi siswa tunarungu dilakukan sebanyak sepuluh kali pertemuan di dalam Kegiatan Belajar Mengajar (KBM) dan lima kali di luar KBM. Latihan di luar KBM dilakukan karena beberapa siswa tunarungu tidak dapat mengikuti pola atau gerakan dengan baik. Latihan dilakukan agar siswa lebih hapal pola tabuh dan gerakan. Adapun pembelajaran rampak kendang dilakukan sesuai dengan langkahlangkah di bawah ini :

Pertemuan Pertama

1. Perkenalan

2. Penjelasan Rampak Kendang

a. Pengertian Rampak Kendang

b. Fungsi Rampak Kendang

3. Pemahaman Unsur Kendang

a. Kendang Besar

b. Kendang Kecil

c. Alat Tabuh Kendang (Stik)

4. Pengkodean Kendang Pengkodean Kendang Untuk

Memudahkan Menghafal Pola Tabuh

a. Angka 1 Sebagai Kode Bahwa Kita Harus Memukul Kendang Besar

b. Angka 2 Sebagai Kode Bahwa Kita Harus Memukul Kendang Kecil Sebelah Kiri

c. Angka 3 Sebagai Kode Bahwa Kita Harus Memukul Kendang Kecil Sebelah Kanan 
Asti Tri Lestari, Anggia Suci Pratiwi

Rikha Surtika Dewi

Pertemuan Kedua

1. Pemutaran Video Rampak Kendang

2. Pemberian Materi Rampak Kendang Pola 1 Berikut Pola Tabuh 1:

$\begin{array}{lllll}21 & 21 & 21 & 11 & 21\end{array}$

Pertemuan Ketiga

1. Pemutaran Video Rampak Kendang

2. Pemberian Materi Rampak Kendang Pola 2

$122222 \quad 31 \longrightarrow$ dilakukan $2 x$

Pertemuan Keempat

1. Pemutaran Video Rampak Kendang

2. Pemberian Materi Rampak Kendang Pola 3

Pola Tabuh 3

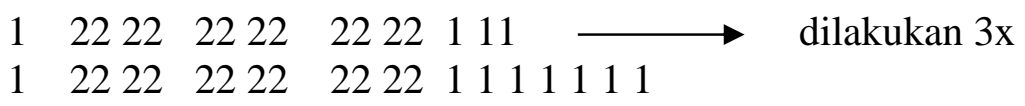

Pertemuan Kelima

1. Pemutaran Video Rampak Kendang

2. Pemberian Materi Rampak Kendang Pola 4

Pola Tabuh 4

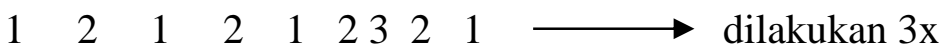

$\begin{array}{lllllllll}1 & 2 & 1 & 2 & 1 & 2 & 3 & 2 & 1111\end{array}$

Pertemuan Keenam

1. Pemutaran Video Rampak Kendang

2. Pemberian Materi Rampak Kendang Pola 5

3. Pemberian Materi Gerak Tari

a. Gerak Tari 1

Jalan Bebek Plaktung Muir $\quad 5 x$

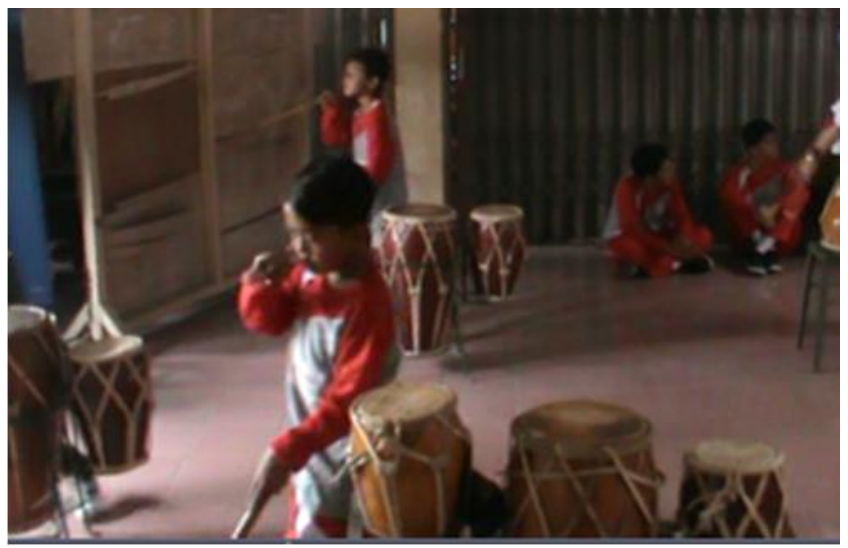

Gambar 4.

Jalan Bebek Plaktung Muir 
Asti Tri Lestari, Anggia Suci Pratiwi

Rikha Surtika Dewi
Pembelajaran Rampak Kendang

dengan Bahasa Isyarat pada Siswa

Tunarungu Di SLB Aisiyah Singaparna

b. Gerak Tari 2

Nyumputan Kendang

$3 x$

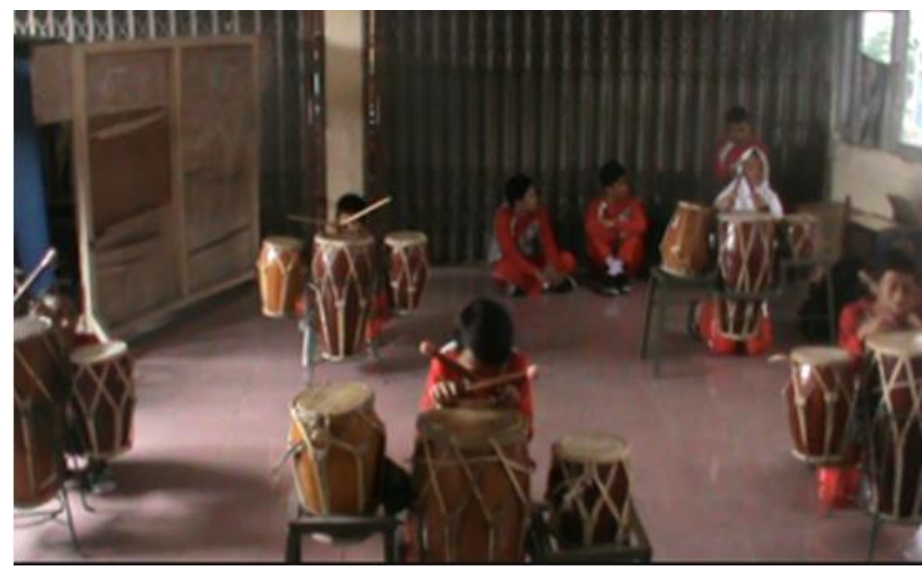

Gambar 5.

Nyumputan Kendang

Pertemuan Ketujuh

1. Pemutaran Video Rampak Kendang

2. Pemberian Materi Rampak Kendang Pola 6

3. Pemberian Materi Gerak Tari
a. Gerak Tari
Torso Tangan L
b. Pola Tabuh 5
11
c. Gerak Tari
Torso Tangan $\mathrm{L}$
d. Pola Tabuh
$21 \quad 2121$
e. Gerak Tari
Torso Tangan L
f. Pola Tabuh
$11 \quad 11111111$
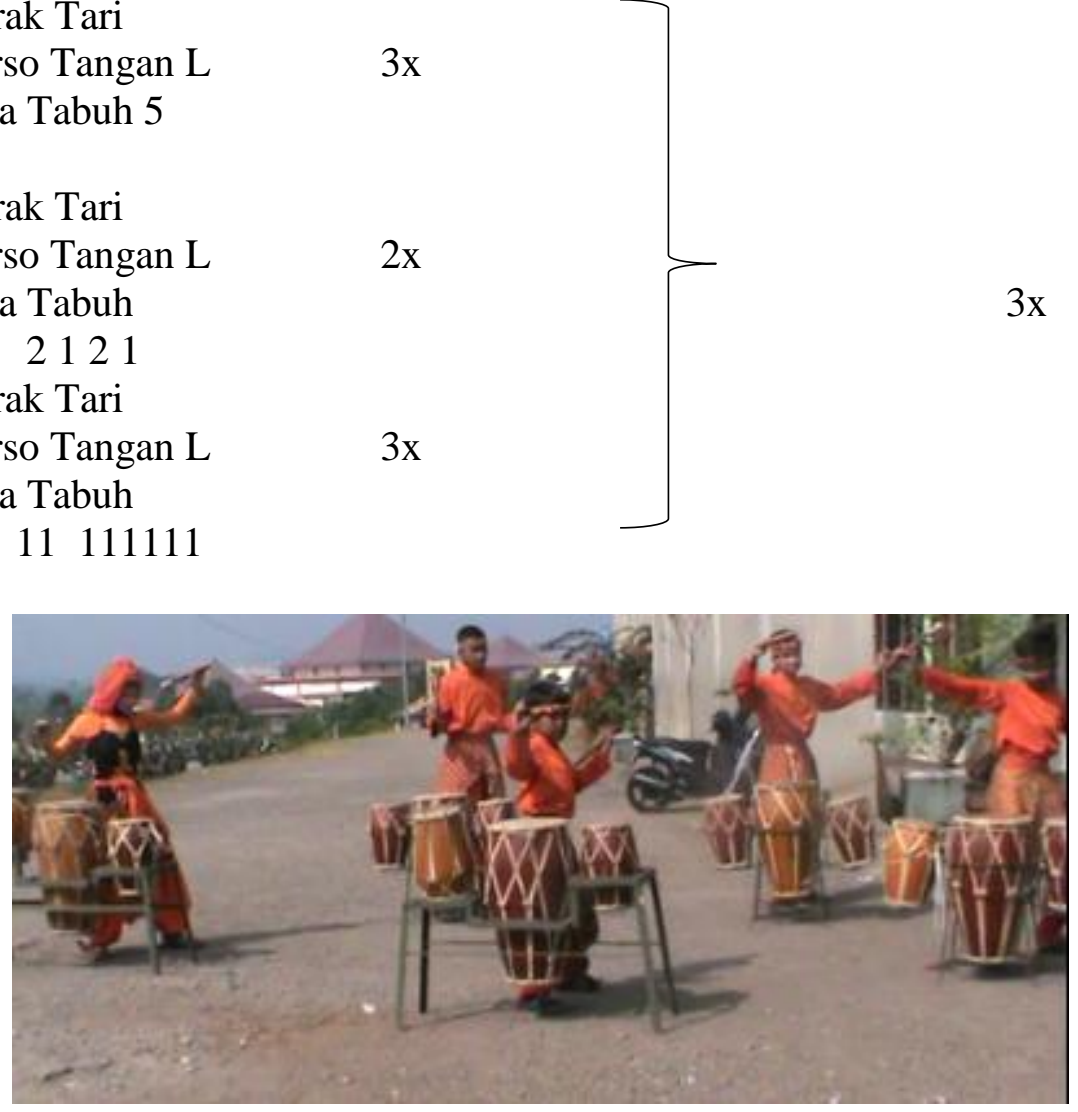

Gambar 6.

Torso Tangan L 
Asti Tri Lestari, Anggia Suci Pratiwi

Rikha Surtika Dewi
Pembelajaran Rampak Kendang

dengan Bahasa Isyarat pada Siswa

Tunarungu Di SLB Aisiyah Singaparna

Pertemuan Kedelapan

1. Pemutaran Video Rampak Kendang

2. Pemberian Materi Rampak Kendang Pola 7

3. Memukul Stik Posisi Stik Berada di Depan Dada dengan Pola Ketuk

a. Taktak Taktaktak Taktaktaktak

b. $11 \quad 1111111$

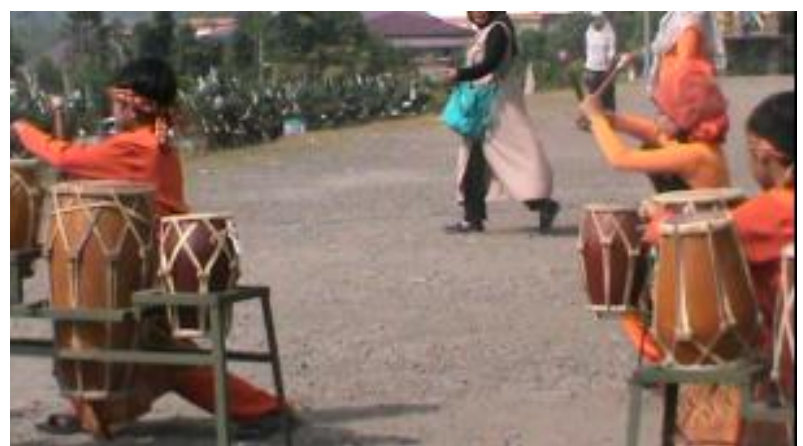

Gambar 7.

Pukul Stik Posisi di Depan Dada

Pertemuan Kesembilan

1. Pemutaran Video Rampak Kendang

2. Pemberian Materi Rampak Kendang Pola 8
a. Gerak Kaki Cewaw
$3 x$
b. Goyang Pinggul Triping $3 x$

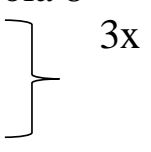

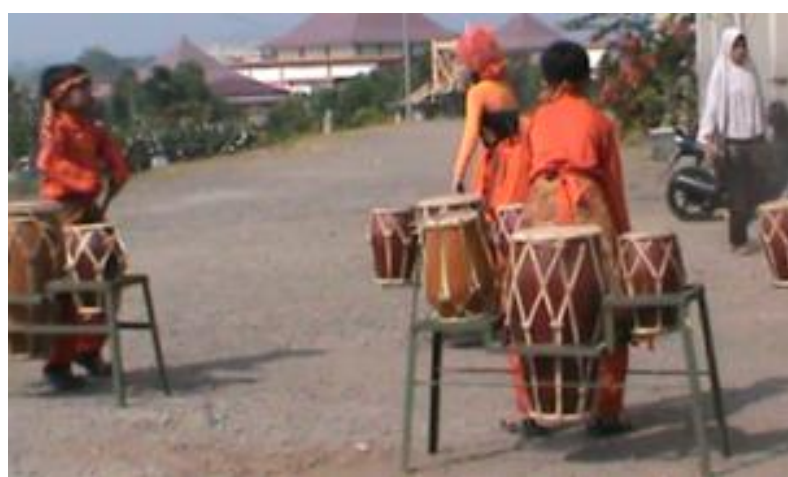

Gambar 8.

Gerak Kaki Cewew

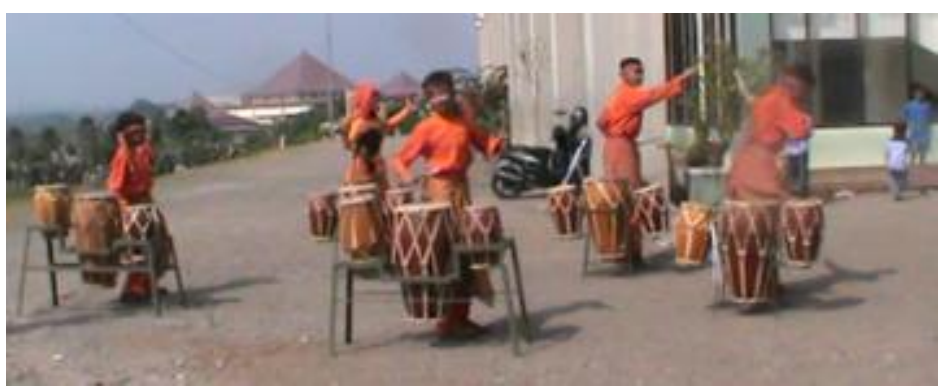

Gambar 9.

Goyang Pinggul Triping 
Pertemuan Kesepuluh

1. Pemutaran Video Rampak Kendang

2. Pemberian Materi Rampak Kendang Pola 9

Pola Tabuh

$$
\begin{array}{llllllll}
111 & 111 & 1111111 & & & \longrightarrow & \\
1 & 1 & 1 & 11111 & 1 & 1 & 1
\end{array} \longrightarrow \begin{aligned}
& 4 x \\
& \text { Putar Stik } 1
\end{aligned}
$$

\section{C.SIMPULAN}

Kendala yang sering dihadapi oleh siswa tunarungu dalam pembelajaran, yaitu masalah komunikasi. Pembelajaran tari tidak terlalu mengalamai kendala karena bersifat visual, namun kendala dihadapi saat harus menggunakan musik dan pergantian gerakan. Untuk keharmonisan musik dan gerak disiasati dengan pengkodean, hitungan, dan ketukan. Di samping kendala-kendala yang dihadapi tersebut, pembelajaran seni tari dengan menggunakan materi yang disukai siswa dan relevan dengan kondisi sosial mayarakat, dalam hal ini Rampak Kendang, dapat meningkatkan minat siswa terhadap pembelajaran seni tari. Berdasarkan hal itu, pembelajaran rampak kendang dengan bahasa isyarat pada siswa tunarungu di SLB Aisiyah Singaparna berhasil diterapkan, serta dapat berjalan dengan optimal, sebagai upaya peningkatan minat dan keterampilan siswa terhadap seni tari.

\section{DAFTAR PUSTAKA}

Cripps, J. H. \& Supalla, S. J. The power of spoken language in schools and deaf students who sign. International Journal of Humanities and Social Science, 2(16), 86-102. 2012.

Mangunsong, Frieda. Psikologi dan Pendidikan Anak Berkebutuhan Khusus Jilid 1. Depok: LPSP3 UI. 2009.

Masunah, Juju \& Narawati. Seni dan Pendidikan Seni (Sebuah Bunga Rampai). Bandung : Pusat Penelitian dan Pengembangan Pendidikan Seni Tradisional (P4ST) Universitas Pendidikan Indonesia. 2003.

Miles and Huberman. Pengolahan Data Kualitataif (Terjemahan Tjetjep Rohendi Rohidi). Semarang: Universitas Negeri Semarang. 1984.

Spencer dan Marc Mars marschark. The Oxford Handbook of Deaf Studies, Language, and Education, vol 2. London: Oxford University Press. 2003. 